\title{
Thermal Processing of PVP- and HPMC-Based Amorphous Solid Dispersions
}

\author{
Justin S. LaFountaine, ${ }^{1,3}$ Leena Kumari Prasad, ${ }^{1}$ Chris Brough, ${ }^{1,2}$ Dave A. Miller, ${ }^{2}$ \\ James W. McGinity, ${ }^{1}$ and Robert O. Williams III ${ }^{1}$
}

Received 27 May 2015; accepted 21 September 2015; published online 13 October 2015

\begin{abstract}
Thermal processing technologies continue to gain interest in pharmaceutical manufacturing. However, the types and grades of polymers that can be utilized in common thermal processing technologies, such as hot-melt extrusion (HME), are often limited by thermal or rheological factors. The objectives of the present study were to compare and contrast two thermal processing methods, HME and KinetiSol ${ }^{\circledR}$ Dispersing (KSD), and investigate the influence of polymer type, polymer molecular weight, and drug loading on the ability to produce amorphous solid dispersions (ASDs) containing the model compound griseofulvin (GRIS). Dispersions were analyzed by a variety of imaging, solid-state, thermal, and solution-state techniques. Dispersions were prepared by both HME and KSD using polyvinylpyrrolidone (PVP) K17 or hydroxypropyl methylcellulose (HPMC) E5. Dispersions were only prepared by KSD using higher molecular weight grades of HPMC and PVP, as these could not be extruded under the conditions selected. Powder X-ray diffraction (PXRD) analysis showed that dispersions prepared by HME were amorphous at $10 \%$ and $20 \%$ drug load; however, it showed significant crystallinity at $40 \%$ drug load. PXRD analysis of KSD samples showed all formulations and drug loads to be amorphous with the exception of trace crystallinity seen in PVP K17 and PVP K30 samples at 40\% drug load. These results were further supported by other analytical techniques. KSD produced amorphous dispersions at higher drug loads than could be prepared by HME, as well as with higher molecular weight polymers that were not processable by HME, due to its higher rate of shear and torque output.
\end{abstract}

KEY WORDS: griseofulvin; hot-melt extrusion; hydroxypropyl methylcellulose; KinetiSol@ Dispersing; polyvinylpyrrolidone.

\section{INTRODUCTION}

Formulation and manufacturing techniques for enhancing bioavailability of poorly soluble active pharmaceutical ingredients (APIs) are of great interest due to the increasing pipeline of these compounds. The dissolution of poorly soluble APIs is often the rate-limiting factor for oral bioavailability $(1,2)$. Solubilityenhancing formulation strategies include particle size reduction and the use of $\mathrm{pH}$ modifiers, salts, co-crystals, pro-drugs, cyclodextrins, lipids, surfactants, self-emulsifying drug delivery systems, mesoporous drug delivery carriers, and amorphous solid dispersions (3-6). The use of amorphous solid dispersions is of great interest in that these high-energy systems tend to lead to orders of magnitude increases in apparent solubility $(7,8)$. As these are typically metastable systems, maintaining physical stability by preventing recrystallization is crucial. Polymers are extremely

\footnotetext{
${ }^{1}$ Division of Pharmaceutics, College of Pharmacy, The University of Texas at Austin, 2409 University Avenue, A1920, Austin, Texas 78712, USA.

${ }^{2}$ DisperSol Technologies, LLC, 111 Cooperative Way, Georgetown, Texas 78626, USA.

${ }^{3}$ To whom correspondence should be addressed. (e-mail: justin.lafountaine@utexas.edu)
}

effective when used to prevent recrystallization (9-12); however, the manufacturing process used may limit the range of polymers that can be utilized. In this study, it was hypothesized that the formulation design space could be increased by using KinetiSol ${ }^{\circledR}$ Dispersing (KSD) as opposed to hot-melt extrusion (HME) for the manufacture of amorphous solid dispersions (ASD), mainly with regard to polymers of increasing molecular weight.

Spray drying (SD) and HME are the most widely used methods of the manufacture of amorphous solid dispersions (13). Spray drying consists of (a) preparation of a feed solution or suspension and (b) atomization of feed solution/suspension and drying gas into a drying chamber leading to (c) solvent evaporation and particle formation. Spray drying is an attractive process due to the ability to engineer final powder properties by manipulating processing parameters (14). The major challenge associated with spray drying is the need to use solvent systems. Organic solvents are flammable, toxic, and costly; therefore, processing with these systems requires limiting exposure to operators, use of explosion proof processing equipment and rooms, and solvent recovery systems. Additionally, the final product must have residual solvent levels below the International Conference on Harmonisation (ICH) requirements, which usually requires a secondary drying step (see USP Chapter $<467>$ Residual Solvents). Lastly, SD processing of high molecular weight polymers, such as PVP K90 and HPMC 
E50, is limited as viscous feed solutions cannot be properly atomized (15).

$\mathrm{HME}$ is a process adapted from the plastics industry consisting of (a) feeding of raw materials (b) conveying, mixing and softening or melting via rotating screws, and (c) shaping, usually through a die and/or calendaring system. The modular setup of an extruder allows for flexibility in tailoring the process for a given formulation, including but not limited to screw design, devolatilization, and liquid injection. This process can also be set up for continuous manufacturing, resulting in reduced costs for high-volume products (16). The drawbacks associated with HME are usually related to the exposure of the product to high processing temperatures for relatively long residence times. Processing of APIs that have high melting points or are thermally labile continues to be a challenge due to energy input required during HME to produce an amorphous final product $(17,18)$. Additionally, higher molecular weight polymers that may be effective for stabilizing the amorphous drug may be too viscous for processing via HME due to high torque loads, requiring the use of plasticizers that decrease the final product glass transition temperature (19-22).

KinetiSol ${ }^{\circledR}$ Dispersing (KSD) is a fusion-based technology for preparing ASDs. The process was adapted from the plastics industry and can be operated in batch mode for screening and early phase studies and in semi-continuous mode for larger quantities (23). The process uses frictional and shear forces to rapidly transition drug-polymer blends into a molten state, resulting in significantly reduced exposures to elevated temperatures. KSD has been shown to produce single-phase ASDs and improved supersaturation properties than those prepared by HME (24-26). The shorter processing times have proved advantageous for thermally labile APIs and polymers $(25,27,28)$. The frictional and shear forces associated with the KSD process have also allowed for processing without plasticizers (29), with high-melting-point APIs (30), and with viscous polymers (28).

The objective of this study was to evaluate the processing and stability of ASDs produced with polymers of increasing molecular weight. Polyvinylpyrrolidone (PVP) and hydroxypropyl methylcellulose (HPMC) of increasing molecular weight were utilized as the carrier polymers and recrystallization inhibitors. Griseofulvin (GRIS) was utilized as the model drug, as it has a relatively high melting point and is known to rapidly recrystallize from its amorphous state (31-33). ASDs of increasing drug load were prepared by HME, if possible, and by KSD. Processed samples were characterized by microscopy, X-ray CT, and SEM to compare the physical appearance and structure of monolithic and milled dispersions. Powder X-ray diffraction (PXRD), modulated differential scanning calorimetry (MDSC), Fourier-transform infrared spectroscopy (FT-IR), and Fourier-transform Raman spectroscopy (FT-Raman) were used to detect crystallinity and FT-IR, and FT-Raman were additionally used to investigate drug-polymer interactions. Samples were placed in open-dish, stability conditions to assess stability over time.

\section{MATERIALS AND METHODS}

\section{Materials}

METHOCELTM E5LV, E15LV, and E50LV grades of hypromellose (HPMC) were kindly donated by The Dow
Chemical Company (Midland, MI, USA). METHOCEL ${ }^{\mathrm{TM}}$ E grades contain $28 \%-30 \%$ methoxyl groups and $7 \%-12 \%$ hydroxypropyl groups (34). Kollidon ${ }^{\circledR}$ K17, K30, and K90F grades of polyvinylpyrrolidone (PVP) were donated by BASF The Chemical Company (Florham Park, NJ, USA). The approximate glass transition temperatures and molecular weights of the HPMC and PVP grades studies are provided in Table I (34-36). Micronized griseofulvin (<30 microns) was purchased from Letco Medical (Decatur, AL, USA), and the same lot was used for all batches. High-performance liquid chromatography-grade acetonitrile, methanol, tetrahydrofuran, and water were purchased from Fisher Scientific (Pittsburgh, PA, USA).

\section{Blending}

Appropriate amounts of GRIS and polymer according to the formulations listed in Table II were placed in $500 \mathrm{~mL}$ or 1 L HDPE bottles, manually mixed for $30 \mathrm{~s}$, and passed through an 18 mesh (1-mm opening) or smaller sieve for deagglomeration. Sieved materials were then blended for 5 min using the Turbula ${ }^{\circledR}$ T2F blender.

\section{Hot-Melt Extrusion}

A co-rotating twin-screw extruder, Leistritz Nano 16 (Leistritz, Sommerville, NJ, USA) was used with a volumetric feeder, Schenk AccuRate (Schenck AccuRate, Whitewater, WI, USA), to prepare the HME samples. Screw speed was maintained at $200 \mathrm{rpm}$ and compositions were extruded through a $3-\mathrm{mm}$ round die. A combination of conveying and kneading elements were used in order from feed zone to the die: $3 \times$ GRA3-20-30, 4× GFA3-15-30, 3×GFA3-10-30, 2×KB7315-30 ${ }^{\circ}, 1 \times$ GRA3-20-30, 1×GFA3-15-30, 1×GFA3-10-30. Extrusion temperature profiles for each of the extruded polymer formulations are reported in Table III. Other polymer formulations were unable to be extruded due to the high viscosity of the polymers resulting in high torque alarms and high pressures, even with the die removed.

\section{KinetiSol® Dispersing}

KSD samples were prepared in a KinetiSol ${ }^{\circledR}$ compounder, designed, and manufactured by DisperSol Technologies, LLC (Georgetown, TX, USA). Blends were loaded into the cylindrical processing chamber of the compounder. A shaft within the processing chamber, having protruding blades, was rotated at a controlled maximum rotational speed of 1800

Table I. Properties of Studied Polymers

\begin{tabular}{llll}
\hline Polymer & Grade & $T_{\mathrm{g}}$ & Molecular weight $(\mathrm{g} / \mathrm{mol})^{\mathrm{a}}$ \\
\hline HPMC & E5 & $170-180$ & 28,700 \\
HPMC & E15 & $170-180$ & 60,300 \\
HPMC & E50 & $170-180$ & 86,700 \\
PVP & K17 & 138 & 9000 \\
PVP & K30 & 149 & 50,000 \\
PVP & K90 & 156 & $1,250,000$ \\
\hline
\end{tabular}

$H P M C$ hydroxypropyl methylcellulose, $P V P$ polyvinylpyrrolidone ${ }^{a}$ Weight-average molecular weight 
Table II. Formulation Compositions (Amounts in $\% w / w$ )

\begin{tabular}{|c|c|c|c|c|c|c|c|}
\hline Formulation & GRIS & PVP K17 & PVP K30 & PVP K90 & HPMC E5 & HPMC E15 & HPMC E50 \\
\hline 1 & 10 & 90 & & & & & \\
\hline 2 & 20 & 80 & & & & & \\
\hline 3 & 40 & 60 & & & & & \\
\hline 4 & 10 & & 90 & & & & \\
\hline 5 & 20 & & 80 & & & & \\
\hline 6 & 40 & & 60 & & & & \\
\hline 7 & 10 & & & 90 & & & \\
\hline 8 & 20 & & & 80 & & & \\
\hline 9 & 40 & & & 60 & & & \\
\hline 10 & 10 & & & & 90 & & \\
\hline 11 & 20 & & & & 80 & & \\
\hline 12 & 40 & & & & 60 & & \\
\hline 13 & 10 & & & & & 90 & \\
\hline 14 & 20 & & & & & 80 & \\
\hline 15 & 40 & & & & & 60 & \\
\hline 16 & 10 & & & & & & 90 \\
\hline 17 & 20 & & & & & & 80 \\
\hline 18 & 40 & & & & & & 60 \\
\hline
\end{tabular}

GRIS griseofulvin, $P V P$ polyvinylpyrrolidone, $H P M C$ hydroxypropyl methylcellulose

$2500 \mathrm{rpm}$ for PVP formulations and $2800 \mathrm{rpm}$ for HPMC formulations with an online control module. Through a combination of high frictional and shearing forces imparted by the rotating blades, without the use of external heat, the temperature of the composition was rapidly increased until a molten mass was achieved. Real-time temperature of the material within the processing chamber was monitored. Once reaching the desired temperature, the mass was automatically ejected from the processing chamber and immediately quenched between two plates. Thermal processing conditions are listed in Table IV.

\section{Milling}

A Fitzpatrick L1A Fitzmill (Fitzpatrick, Inc., Elmhurst, IN, USA) was used to mill HME and KSD materials. PVP HME and KSD samples were milled in the impact configuration at 8000-rpm impellor speed with a 0.033 " round-hole screen. HPMC HME samples were milled in the knives configuration, also at $8000 \mathrm{rpm}$ with the 0.033 " round-hole screen. HPMC KSD samples were milled using the knives configuration at $8000 \mathrm{rpm}$, but with two passes through the mill-the first with a 0.65 " screen and the second with a 0.033 " screen.

\section{Optical Microscopy}

Imaging was performed using a Leica DFC310X digital camera mounted on a Leica M205 stereo microscope (Buffalo

Table III. Nano-16 Temperature Profiles

\begin{tabular}{lllll}
\hline \multirow{2}{*}{ Polymer } & \multicolumn{4}{l}{ Temperature profile $\left({ }^{\circ} \mathrm{C}\right)$} \\
& Zone 1 & Zone 2 & Zone 3 & Die \\
\hline PVP K17 & 100 & 150 & 165 & 165 \\
HPMC E5 & 100 & 150 & 175 & 180 \\
\hline
\end{tabular}

PVP polyvinylpyrrolidone, HPMC hydroxypropyl methylcellulose
Grove, IL). All images were taken with $\times 20$ zoom using Leica application suite 3.4.0. Samples containing 20\% GRIS in PVP K17 or HPMC E5 were chosen for analysis to directly compare processing methods.

\section{X-Ray Computed Tomography}

For micro-CT imaging, monolithic samples (pre-milling) of HME and KSD processed material with a diameter of approximately $2 \mathrm{~mm}$ were analyzed. Samples containing $20 \%$ GRIS in PVP K17 or HPMC E5 were chosen for analysis to directly compare processing methods. The imaging was performed on an Xradia microXCT 400 (Carl Zeiss, Oberkochen, Germany) at the High-Resolution X-ray CT Facility at The University of Texas at Austin (UTCT). Each data set comprises 979 slices with a voxel size of $2.2 \mu \mathrm{m}$. Samples containing PVP were scanned using the following parameters: $\times 10$ objective, $50 \mathrm{kV}, 10 \mathrm{~W}, 5 \mathrm{~s}$ acquisition time, detector $8 \mathrm{~mm}$, source $-37 \mathrm{~mm}$, camera bin 2 , angles \pm 180 , 1261 views, no filter. They were reconstructed with beam hardening correction 0.8 , byte scaling [-200, 4500], and recon filter smooth (kernel size=0.5). Samples containing HPMC were scanned using the following parameters: $\times 10$ objective,

Table IV. KSD Compounder Processing Conditions

\begin{tabular}{lll}
\hline Polymer & Processing speed (rpm) & $\begin{array}{c}\text { Ejection } \\
\text { temperature }\left({ }^{\circ} \mathrm{C}\right)\end{array}$ \\
\hline PVP K17 & 2200 & 138 \\
PVP K30 & $2200,2500(40 \%$ drug load $)$ & 150 \\
PVP K90 & $2500,1800(40 \%$ drug load $)$ & 156,140 \\
& & $(40 \%$ drug load $)$ \\
HPMC E5 & 2800 & 150 \\
HPMC E15 & 2800 & 160 \\
HPMC E50 & 2800 & 160 \\
\hline
\end{tabular}

PVP polyvinylpyrrolidone, HPMC hydroxypropyl methylcellulose 
$70 \mathrm{kV}, 10 \mathrm{~W}, 3.75 \mathrm{~s}$ acquisition time, detector $8 \mathrm{~mm}$, source $-37 \mathrm{~mm}$, camera bin 2 , angles $\pm 180,721$ views, no filter. They were reconstructed with beam hardening correction 0 , byte scaling $[-80,470]$, and recon filter smooth (kernel size $=0.5)$.

\section{Scanning Electron Microscopy}

The surface morphology of the milled dispersion particles was imaged by scanning electron microscopy (SEM). Samples containing $20 \%$ GRIS in PVP K17 or HPMC E5 were chosen for analysis to directly compare processing methods. Samples were mounted onto pin stubs using conductive carbon adhesive tape and sputter coated with a 12-nm thickness of palladium/platinum under argon using a Cressington 208HR sputter coater (Cressington, Watford, UK). The Zeiss Supra field emission SEM (Zeiss, Oberkochen, Germany) was operated at an accelerating voltage of $5 \mathrm{kV}$.

\section{Powder X-Ray Diffraction}

PXRD analyses were conducted using Bruker-D8 diffractometer (Billerica, MA, USA) equipped with $\mathrm{CuK} \alpha$ radiation $(1.54 \AA)$ at $40 \mathrm{kV}, 40 \mathrm{~mA}$ passing through Ni filter with a scintillation counter detector. Instrument was calibrated for accuracy of peak positions using quartz. Data was collected in a continuous scan mode with a step size of $0.02^{\circ}$ and step time of $2 \mathrm{~s}$ over a of $2 \theta$ range of $10^{\circ}$ to $50^{\circ}$ for initial samples and $10^{\circ}$ to $35^{\circ}$ for stability samples. No significant diffraction peaks were observed below $10^{\circ}$ for the materials analyzed during initial screening. Analysis was performed with DIFFRAC ${ }^{\text {plus }}$ EVA diffraction software, version 15.0 (Bruker AXS, Billerica, MA, USA).

\section{Modulated Differential Scanning Calorimetry}

MDSC was utilized to determine the presence of crystalline GRIS and/or the glass transition temperatures of prepared ASDs. Samples were placed into Tzero aluminum pans and crimped using the Tzero press. Prepared samples were placed in a TA Instruments Model Auto Q20 DSC (TA Instruments, New Castle, DE, USA) and heated to $105^{\circ} \mathrm{C}$ for 5-10 $\mathrm{min}$ to remove residual moisture. Samples were then equilibrated at $25^{\circ} \mathrm{C}$ and then heated to $250^{\circ} \mathrm{C}$ at a ramp rate of $5^{\circ} \mathrm{C} / \mathrm{min}$ with a modulation amplitude and period of $1^{\circ} \mathrm{C}$ and $60 \mathrm{~s}$, respectively. During analyses, high-purity nitrogen flowed through the sample chamber at a rate of $50 \mathrm{~mL} / \mathrm{min}$. Both non-reversible and reversible heat flows of all samples were monitored and analyzed using TA Universal Analysis 2000 software.

\section{Fourier-Transform Infrared Spectroscopy}

The FT-IR spectrum of crystalline griseofulvin, amorphous griseofulvin, individual polymers, and dispersions were recorded using a Nicolet ${ }^{\mathrm{TM}}$ iS ${ }^{\mathrm{TM}} 50$ spectrometer (Thermo Scientific, Waltham, MA, USA) with an Attenuated Total Reflectance (ATR) accessory in the wavenumber range between 2000 and 700. Each spectrum was an average of 32 scans with a resolution of $4 \mathrm{~cm}^{-1}$. Data collection and analysis were performed with OMNIC TM (Thermo Scientific, Waltham, MA, USA). Pure amorphous griseofulvin was prepared by heating above the melting point in a temperaturecontrolled oven, followed by quenching in liquid nitrogen, and confirmed by DSC.

\section{Fourier-Transform Raman Spectroscopy}

The FT-Raman spectrum of crystalline griseofulvin, amorphous griseofulvin, individual polymers, and dispersions were recorded using the Nicolet $^{\mathrm{TM}}$ iS ${ }^{\mathrm{TM}} 50$ Raman module mounted into the Nicolet ${ }^{\mathrm{TM}}$ iS ${ }^{\mathrm{TM}} 50$ spectrometer (Thermo Scientific, Waltham, MA, USA). A single point, defocused laser $(1064 \mathrm{~nm})$, powered to $0.4 \mathrm{~W}$, was used for excitation, and each spectrum was collected between 3600 and $500 \mathrm{~cm}^{-1}$. An average of 64 scans was collected for each spectrum with a resolution of $4 \mathrm{~cm}^{-1}$. Data collection and analysis were performed with OMNICTM.

\section{Potency Testing}

Aliquots of solid dispersions were weighed and accurately transferred into volumetric flasks to prepare 1.25 or $0.625 \mathrm{mg} / \mathrm{mL}$ solutions. PVP samples were prepared with methanol and HPMC samples were prepared with water and methanol (1:1). These solutions were diluted further with mobile phase (see "High-Performance Liquid Chromatography" section) to produce a final theoretical concentration of $0.125 \mathrm{mg} / \mathrm{mL}$. The diluted samples were then filtered through $0.22 \mu \mathrm{m}$ 13-mm Millex-GV PVDF filters (Millipore, Billerica, MA) and immediately transferred to 2-mL high-performance liquid chromatography (HPLC) vials for analysis.

\section{High-Performance Liquid Chromatography}

GRIS content was analyzed with a Thermo Scientific Dionex UltiMate 3000 HPLC system (Thermo Scientific, Sunnyvale, CA, USA) based on the USP Assay method for griseofulvin tablets. An Ultimate 3000 Autosampler was utilized to consistently inject $20-\mu \mathrm{L}$ samples. The HPLC system also included dual UltiMate 3000 Pumps and an UltiMate RS Variable Wavelength Detector. The system was operated under isocratic conditions with a water, acetonitrile, and tetrahydrofuran (60:35:5) mobile phase, with a flow rate of $1 \mathrm{ml} /$ min. Injections were passed through a Dionex Acclaim ${ }^{\circledR} 120$ C18 reverse phase column, $4.6 \times 250 \mathrm{~mm}, 5-\mu \mathrm{m}$ packing (Thermo Scientific, Sunnyvale, CA, USA), and absorbance at a wavelength of $254 \mathrm{~nm}$ was measured. The column was kept at $25^{\circ} \mathrm{C}$. Chromeleon Version 6.80 software (Thermo Scientific, Sunnyvale, CA, USA) was used to process all chromatography data.

\section{Thermogravimetric Analysis}

A Mettler Thermogravimetric Analyzer, Model TGA/ DSC 1 (Columbus, OH, USA), was utilized to evaluate the moisture content of the ASD samples, bracketed at $10 \%$ and $40 \%$ drug load. Samples were weighed into individual $70-\mu \mathrm{L}$ alumina crucibles with lids. Sample mass was monitored as the temperature was increased to $105^{\circ} \mathrm{C}$ for $10 \mathrm{~min}$. Weight loss (\%) was analyzed using STARe software (Columbus, OH, USA). 


\section{Stability Studies}

Solid dispersions were allocated into 20 -mL glass scintillation vials, approximately 5 g per vial, labeled accordingly and placed, open dish, in stability conditions for 6 months. Stability conditions were prepared using saturated salt solutions and/or ovens to produce the following conditions: $25^{\circ} \mathrm{C}$ (Drierite desiccant), $25^{\circ} \mathrm{C} / 60 \% \mathrm{RH}$, and $40^{\circ} \mathrm{C}$ (Drierite desiccant), and $40^{\circ} \mathrm{C} / 43 \% \mathrm{RH}$. The latter was chosen in lieu of ICH guidelines of $40^{\circ} \mathrm{C} / 75 \% \mathrm{RH}$ to prevent deliquescence of PVP systems, which would make the compositions difficult to characterize.

\section{RESULTS}

\section{Processing and Appearance}

Dispersions using PVP K17 and HPMC E5 were processed by both HME and KSD. Dispersions using PVP K30, PVP K90, HPMC E15, and HPMC E50 were only processed by KSD, as these high-viscosity polymers could not be extruded. In an effort to compare the appearance and morphological differences in samples produced by different processing methods, the $20 \%$ drug load samples in PVP K17 and HPMC E5 prepared by HME and KSD were imaged by a variety of techniques including stereo microscopy (Fig. 1, top row), Xray $\mathrm{CT}$ (Fig. 1, middle row), and SEM (Fig. 1, bottom row). As shown in Fig. 1, there are a number of differences observed. Samples prepared by HME are darker but more transparent in comparison to samples prepared by KSD. The opacity of the KSD samples are explained by the entrapped air that is apparent in the X-ray CT images, which show air pockets distributed throughout the sample (note, the diameter of the $\mathrm{X}$-ray CT field of view is $2 \mathrm{~mm}$ ). This is in contrast to the HME prepared samples that have uniform density through the entire volume of the sample. The porosity of the KSD processed samples is then further observed in the SEM images of milled particles, particularly in cases where the milled particles are relatively large compared to the size of the pores, as in the case of the HPMC samples. An overall summary of the physical appearance observations is provided in Table V. In reference to color, the top row of Fig. 1 provides an example of yellow, off-white, dark brown, and light brown, respectively, from left to right.

\section{Physicochemical Characterization}

Potency testing by HPLC was bracketed, with only $10 \%$ and $40 \%$ drug load samples analyzed. All processed samples tested yielded potency within USP limits between $90 \%$ and $115 \%$ of label claim, with no degradation peaks observed in HPLC analysis. The amorphous nature of the prepared compositions was confirmed using PXRD. Most compositions were amorphous with the exception of the $40 \%$ drug load HME formulations using PVP K17 and HMPC E5 (Fig. 2a, c); additionally, trace crystallinity was also seen in the $40 \%$ drug load KSD formulations using PVP K17 and PVP K30 (Fig. 2b).

The prepared dispersions were also evaluated using MDSC. The thermograms of the PVP formulations correlated with the results from the PXRD analysis, showing a melt endotherm for the $40 \%$ drug load HME and KSD formulations using PVP K17, as well as a very trace melt endotherm for the $40 \%$ drug load KSD formulation using PVP K30. The thermogram for the $40 \%$ drug load HME formulation using HPMC E5 showed a melt endotherm, correlating with the PXRD data; however, endotherms were also seen in the $20 \%$ and $40 \%$ drug load KSD formulations using all grades of HPMC. Upon further evaluation, a broad recrystallization exotherm was observed in the $20 \%$ and $40 \%$ drug load HPMC

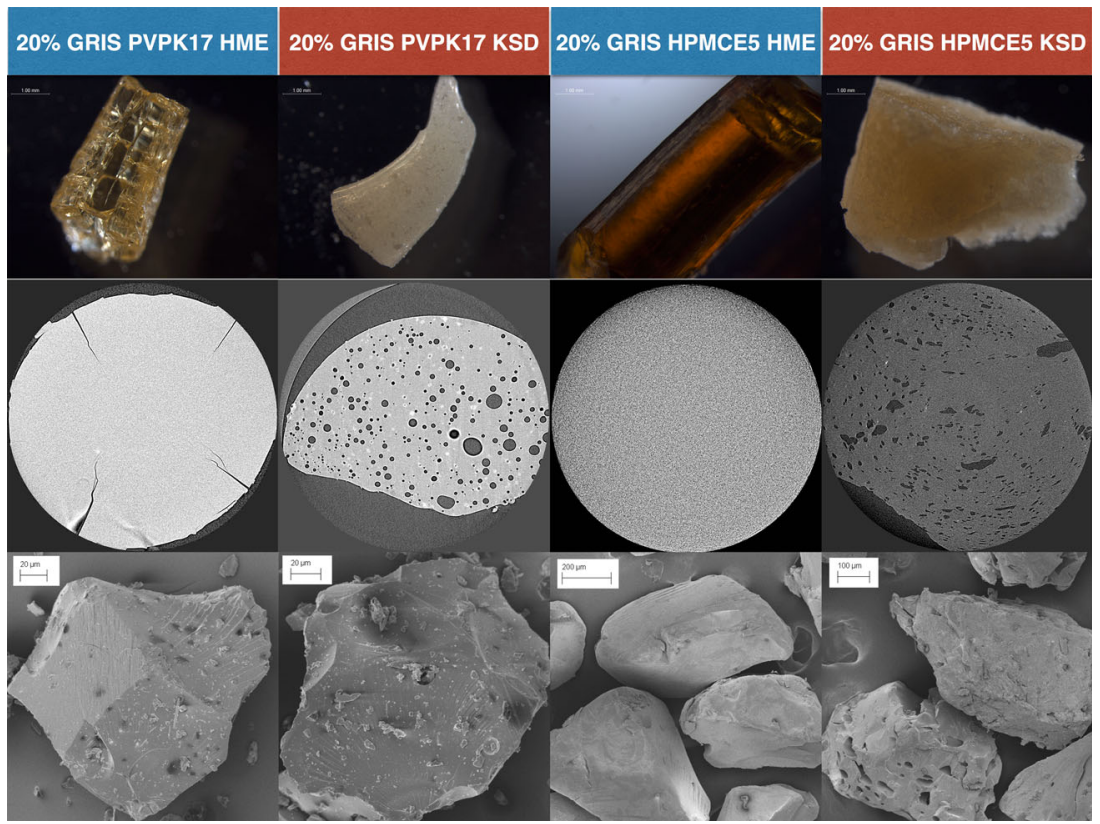

Fig. 1. Stereo microscopy (top row), X-ray computed tomography (middle row), and scanning electron microscopy (bottom row) images of amorphous solid dispersions containing 20\% GRIS in PVP K17, HME processed (column 1) and KSD processed (column 2), and HPMC E5, HME processed (column 3) and KSD processed (column 4) 
Table V. Appearance of Processed Batches

\begin{tabular}{|c|c|c|c|c|c|}
\hline Drug load (\%) & Polymer & Process & Color & Clarity & Porosity \\
\hline 10 & PVP K17 & HME & Yellow & Transparent & - \\
\hline 20 & PVP K17 & HME & Yellow & Transparent & - \\
\hline 40 & PVP K17 & HME & Yellow & Opaque & - \\
\hline 10 & HPMC E5 & HME & Dark brown & Transparent & - \\
\hline 20 & HPMC E5 & HME & Dark brown & Transparent & - \\
\hline 40 & HPMC E5 & HME & Brown & Opaque & - \\
\hline 10 & PVP K17 & KSD & Off-white & Opaque & + \\
\hline 20 & PVP K17 & KSD & Off-white & Opaque & + \\
\hline 40 & PVP K17 & KSD & Off-white & Opaque & + \\
\hline 10 & PVP K30 & KSD & Light brown & Opaque & + \\
\hline 20 & PVP K30 & KSD & Light brown & Opaque & + \\
\hline 40 & PVP K30 & $\mathrm{KSD}$ & Light brown & Opaque & + \\
\hline 10 & PVP K90 & KSD & Light brown & Opaque & + \\
\hline 20 & PVP K90 & KSD & Light brown & Opaque & + \\
\hline 40 & PVP K90 & KSD & Light brown & Opaque & + \\
\hline 10 & HPMC E5 & KSD & Light brown & Opaque & + \\
\hline 20 & HPMC E5 & KSD & Light brown & Opaque & + \\
\hline 40 & HPMC E5 & $\mathrm{KSD}$ & Light brown & Opaque & + \\
\hline 10 & HPMC E15 & KSD & Light brown & Opaque & + \\
\hline 20 & HPMC E15 & KSD & Light brown & Opaque & + \\
\hline 40 & HPMC E15 & $\mathrm{KSD}$ & Light brown & Opaque & + \\
\hline 10 & HPMC E50 & KSD & Light brown & Opaque & + \\
\hline 20 & HPMC E50 & $\mathrm{KSD}$ & Light brown & Opaque & + \\
\hline 40 & HPMC E50 & KSD & Light brown & Opaque & + \\
\hline
\end{tabular}

PVP polyvinylpyrrolidone, HPMC hydroxypropyl methylcellulose, $H M E$ hot-melt extrusion, $K S D$ KinetiSol ${ }^{\circ}$ Dispersing

samples in the non-reversible heat flow thermograms, while no recrystallization exotherms were observed in the $10 \%$ drug loading samples or in any of the PVP samples. A summary of the MDSC data is provided in Table VI, including the glass transition temperature measured at the inflection point, the maximum endotherm temperature, if present, in reversing heat flow measurements, and the presence of a broad exotherm just prior to the melt endotherm in non-reversing heat flow.

Crystalline and amorphous GRIS was analyzed by FT-IR and FT-Raman as shown in Fig. 3a, b, respectively. In FT-IR, peak broadening is observed in the two carbonyl stretching regions at $\sim 1712$ and $\sim 1662 \mathrm{~cm}^{-1}$ for the benzofuran ring and cyclohexane, respectively (37). Additionally, the triplet at $\sim 1600 \mathrm{~cm}^{-1}$ becomes a doublet in the amorphous form and several other doublet peaks such as those at $\sim 1210$ and $\sim 1340 \mathrm{~cm}^{-1}$ become single peaks. Similar observations can be made in the FT-Raman data with increased diffusion in the $\mathrm{C}-\mathrm{H}$ stretching region at $\sim 3000 \mathrm{~cm}^{-1}$, a doublet becoming a single peak at $\sim 640 \mathrm{~cm}^{-1}$, and a significant reduction in peak intensity at $\sim 840 \mathrm{~cm}^{-1}$ with the amorphous form of GRIS, with similar observations made by other researchers (38).

The FT-IR spectra of amorphous GRIS, polymers, and processed dispersions are shown in Fig. 4. The carbonyl group of PVP is observed at $\sim 1670 \mathrm{~cm}^{-1}$, and the combination bands attributed to $\mathrm{C}-\mathrm{O}$ stretching and secondary hydroxyl groups in HPMC are observed at $\sim 1060 \mathrm{~cm}^{-1}$ with a shoulder at $\sim 1115 \mathrm{~cm}^{-1}$, respectively. None of these peaks nor the GRIS peaks previously shown in Fig. 3 that are distinguishable in the processed dispersion are observed to shift in relation to increasing drug load, processing method, or increasing polymer molecular weight, suggesting a lack of interaction between GRIS and PVP or HPMC. As previously described, a singlet peak at $1210 \mathrm{~cm}^{-1}$ is associated with amorphous GRIS, but the appearance of a doublet at the same wavelength is associated with crystalline GRIS and can be observed in the $40 \%$ drug load samples prepared by HME, which complements PXRD and MDSC data.

In agreement with the FT-IR data, no evidence of specific interactions between GRIS and PVP or HPMC is observed in the FT-Raman spectra shown in Fig. 5. Again, features corresponding to crystalline GRIS can be observed in the $40 \%$ drug load dispersions prepare by HME such as the doublet peak at $\sim 640 \mathrm{~cm}^{-1}$.

\section{Stability}

After 6 months in open-dish stability conditions, all formulations were physically and chemically unchanged, with no increase in peak intensity by PXRD and no observed degradation peaks in HPLC (data not shown). Representative PXRD profiles of each of the dispersions stored at the most aggressive conditions $\left(40^{\circ} \mathrm{C} / 43 \% \mathrm{RH}\right)$ are shown in Fig. 6 . No significant increases in peak intensity are observed compared to the initial analysis (Fig. 2), despite moisture contents of $8 \%$ to $12 \%$ for PVP compositions and $1 \%$ to $3 \%$ for HPMC compositions as measured by TGA.

\section{DISCUSSION}

The two polymers selected for this study, PVP and HPMC, were chosen because they are commonly utilized in amorphous solid dispersions and are available in varying molecular weights (39-41). The two polymers also have opposing mechanisms of hydrogen bonding, with HPMC acting as a proton donor and PVP acting as a proton acceptor. Higher 

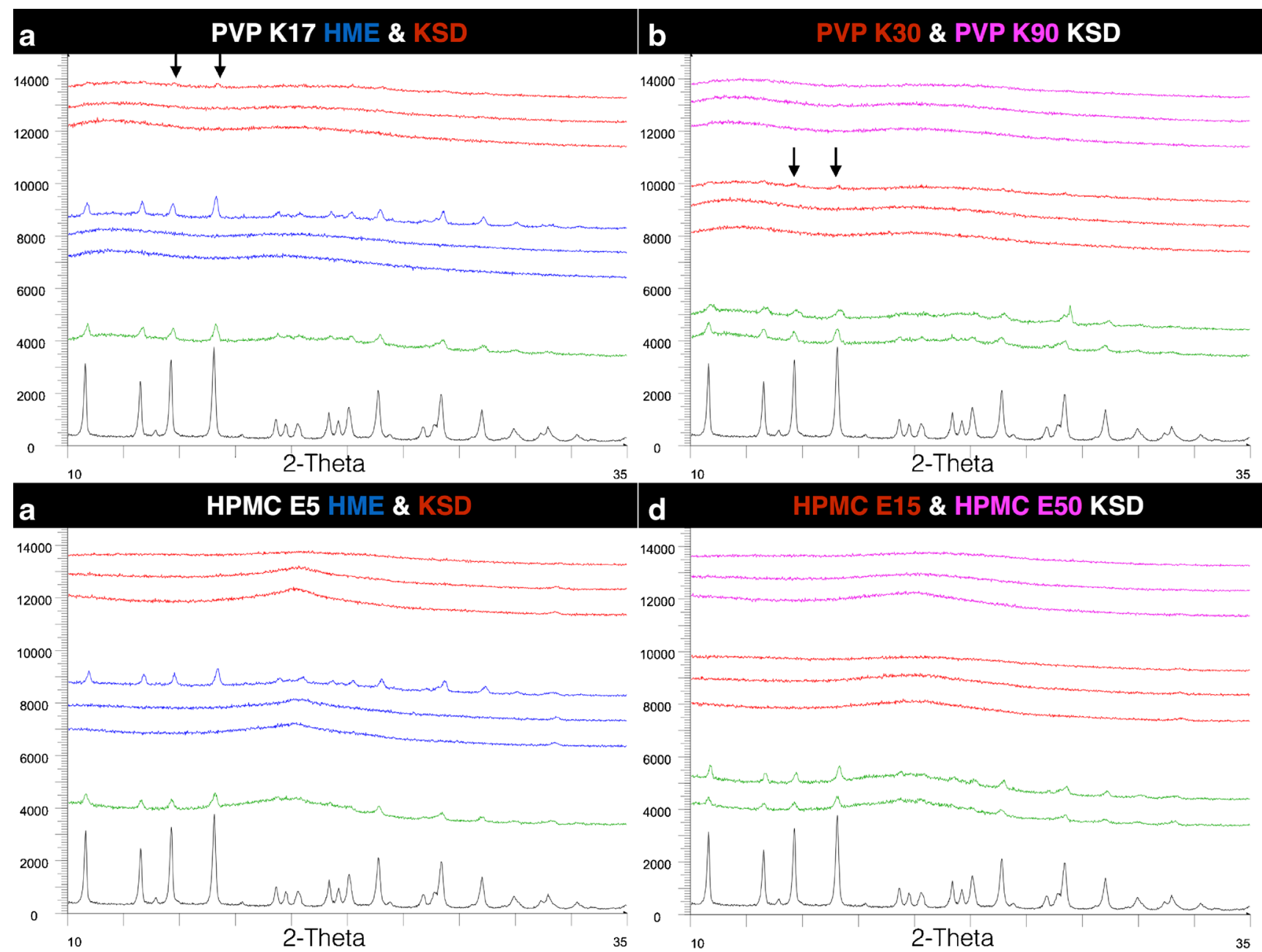
10 2-Theta

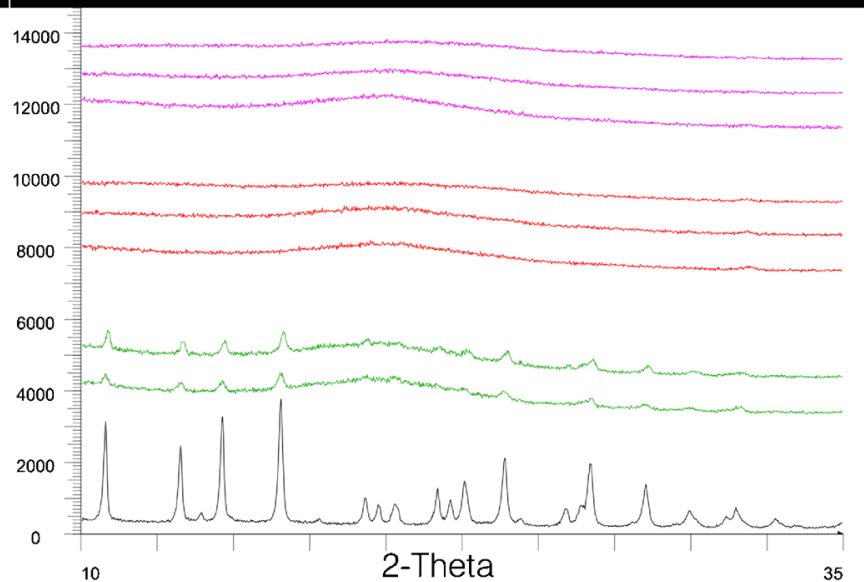

Fig. 2. PXRD profiles (from bottom to top) of GRIS crystalline drug (- -), 10\% drug load physical mixtures (--), HME processed dispersions (- $)$, and KSD processed dispersions (- ) (from $10 \%$ to $40 \%$ drug load) in a (PVP K17) and $\mathbf{c}$ (HPMC E5). KSD processed dispersions of PVPK30 (--) and PVP K90 (--) (from $10 \%$ to $40 \%$ drug load) in b and KSD processed dispersions of HPMC E15 (--) and HMPC E50 (--) (from $10 \%$ to $40 \%$ drug load) in d. Areas of observed trace crystallinity are marked with arrows

molecular weight polymers can aid in preventing nucleation and crystal growth in a supersaturated environment due to increased viscosity and therefore decreased molecular mobility $(12,28,42)$. The ability of a polymer to hydrogen bond with a drug allows for molecular stabilization, another mechanism that can prevent recrystallization (7). GRIS has been characterized as a proton acceptor and has been shown to form hydrogen bonds with other proton-donating polymers, such as HPMC-acetate succinate (43) and poly[N-(2hydroxypropyl)methacrylate] (44). However, while GRIS is not expected to interact with PVP, it additionally does not interact with the E chemistry of HPMC as observed by FTIR and FT-Raman in this study. This may be due to steric effects and/or the low substitution of hydroxypropyl groups. Thus, decreased molecular mobility alone due to the antiplasticization of the polymer would account for the physical stability of the solid dispersions in this study, a sole mechanism that has been observed in other solid dispersion systems (12).

The PVP K17 formulations prepared by HME were processed at $165^{\circ} \mathrm{C}$, approximately $30^{\circ} \mathrm{C}$ above the polymer $T_{\mathrm{g}}$ to produce the clear extrudate at $10 \%$ and $20 \%$ drug load. The extrudate at $40 \%$ drug load was phase separated, producing an opaque extrudate. The processing temperature was not increased as PVP $\mathrm{K} 17$ is known to degrade at $175^{\circ} \mathrm{C}$ (45). Extrusion attempts with PVP K30 resulted in high torque alarms, and extrusion with PVP K90 was not conducted based on the limitations seen with PVP K30. Extrusion of PVP K30 and K90 has been previously studied and usually requires the use of a plasticizer to aid in processing $(46,47)$. Fousteris et al. utilized Poloxamer 188 at $5 \%$ and $10 \%$ as a plasticizer with PVP K30. This allowed HME processing at $120^{\circ} \mathrm{C}$, approximately $30^{\circ} \mathrm{C}$ lower than the polymer $T_{\mathrm{g}}$; however, processing with a crystalline plasticizer resulted in an opaque extrudate. As clarity of extrudate is often used as a quality control, this would be an undesirable quality of an extrudate product. Ghebremeskel et al. utilized polysorbate 80 and docusate sodium to plasticize formulations of PVP K30 and showed reductions in the torque during extrusion when processed with plasticizer, with more significant reductions seen with the polysorbate 80 formulation. Both formulations showed significant reductions in die pressure at the lower processing temperature evaluated. APIs with miscibility in a polymer can also contribute a plasticizing effect on a formulation $(48,49)$. Chokshi et al. showed that $30 \%$ drug load formulations of indomethacin in PVP K30 degraded when conducting shear viscosity readings. At drug loads of $50 \%$ and $70 \%$, a reduction 
Table VI. MDSC Results of Processed Batches

\begin{tabular}{|c|c|c|c|c|c|}
\hline Drug load (\%) & Polymer & Process & $T_{\mathrm{g}}\left({ }^{\circ} \mathrm{C}\right)$ & Melt endotherm $\left({ }^{\circ} \mathrm{C}\right)$ & Recrystallization exotherm \\
\hline 10 & PVP K17 & HME & 132 & - & - \\
\hline 20 & PVP K17 & HME & 126 & - & - \\
\hline 40 & PVP K17 & HME & 120 & 195 & - \\
\hline 10 & HPMC E5 & HME & 114 & - & - \\
\hline 20 & HPMC E5 & HME & 98 & - & - \\
\hline 40 & HPMC E5 & HME & 90 & 209 & + \\
\hline 10 & PVP K17 & KSD & 133 & - & - \\
\hline 20 & PVP K17 & KSD & 125 & - & - \\
\hline 40 & PVP K17 & KSD & 113 & 196 & - \\
\hline 10 & PVP K30 & KSD & 152 & - & - \\
\hline 20 & PVP K30 & KSD & 142 & - & - \\
\hline 40 & PVP K30 & KSD & 123 & 203 & - \\
\hline 10 & PVP K90 & $\mathrm{KSD}$ & 166 & - & - \\
\hline 20 & PVP K90 & KSD & 141 & - & - \\
\hline 40 & PVP K90 & KSD & 131 & - & - \\
\hline 10 & HPMC E5 & KSD & 112 & - & - \\
\hline 20 & HPMC E5 & KSD & 100 & 204 & + \\
\hline 40 & HPMC E5 & $\mathrm{KSD}$ & 89 & 211 & + \\
\hline 10 & HPMC E15 & $\mathrm{KSD}$ & 115 & - & - \\
\hline 20 & HPMC E15 & KSD & 108 & 207 & + \\
\hline 40 & HPMC E15 & KSD & 90 & 214 & + \\
\hline 10 & HPMC E50 & KSD & 127 & - & - \\
\hline 20 & HPMC E50 & KSD & 110 & 207 & + \\
\hline 40 & HPMC E50 & KSD & 91 & 213 & + \\
\hline
\end{tabular}

$P V P$ polyvinylpyrrolidone, $H P M C$ hydroxypropyl methylcellulose, $H M E$ hot-melt extrusion, $K S D$ KinetiSol ${ }^{\circledR}$ Dispersing

in softening temperature was observed, allowing for HME processing at temperatures around $150^{\circ} \mathrm{C}$. Given the plasticization effect of GRIS $\left(T_{\mathrm{g}}=\sim 89^{\circ} \mathrm{C}, \mathrm{Tm}=\sim 220^{\circ} \mathrm{C}\right.$; (31)), as observed by a decrease in $T_{\mathrm{g}}$ in MDSC experiments, a higher drug loading could allow for further reduction in viscosity of high molecular weight polymer grades to enable extrusion processing. However, given the relatively high melting point of GRIS and that higher drug loads were crystalline within the parameters evaluated, increasing drug loads would be more difficult to render amorphous. Given the outcome of this study, an interesting future study would be to further evaluate shear effects in extrusion processing by utilizing more aggressive screw design and increased screw speed.

The thermal and rheological behaviors of PVPs have been well studied; thus, it was expected that extrusion of
PVP K30 and K90 would be difficult or impossible (50). PVP $\mathrm{K} 30$ and $\mathrm{K} 90$ have glass transition temperatures around $149^{\circ} \mathrm{C}$ and $156^{\circ} \mathrm{C}$ and are known to degrade around $175^{\circ} \mathrm{C}$ and $200^{\circ} \mathrm{C}$, respectively. Although this leaves a thermal processing window of approximately $25^{\circ} \mathrm{C}-50^{\circ} \mathrm{C}$, the complex viscosity of these two polymers does not reach the optimal range for extrusion $(1-10 \mathrm{kPa} * \mathrm{~s})$ until above $200^{\circ} \mathrm{C}(45,50)$. These thermal and rheological limitations of certain high-viscosity polymers are where KSD can provide a processing option.

All three PVP grades and drug loads could be processed by KSD. Ejection temperatures were set at the $T_{\mathrm{g}}$ of the polymer, with the exception of the PVP K90 40\% drug load formulation. A lower processing speed and ejection temperature was utilized for the PVP K90 40\% drug load formulation, as some browning of the polymer was observed at the
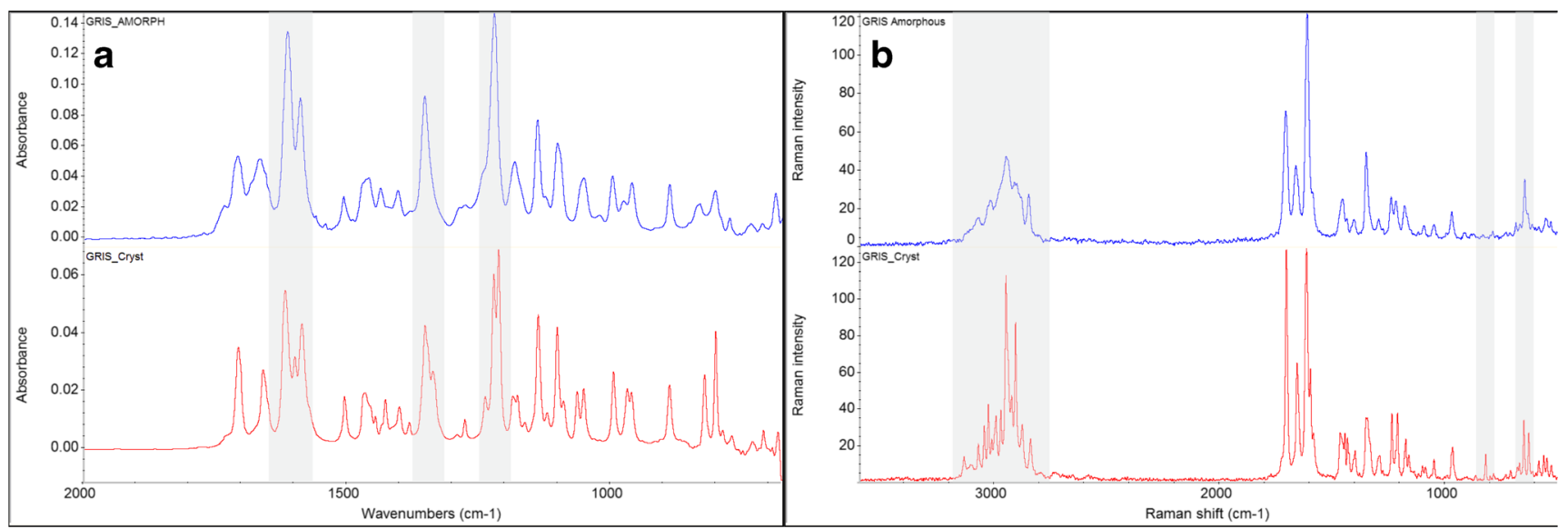

Fig. 3. FT-IR spectra of crystalline (--) and amorphous (--) griseofulvin in a and FT-Raman spectra of crystalline (--) and amorphous (--) griseofulvin in $\mathbf{b}$. Notable regions of differential features between crystalline and amorphous drug are shaded 

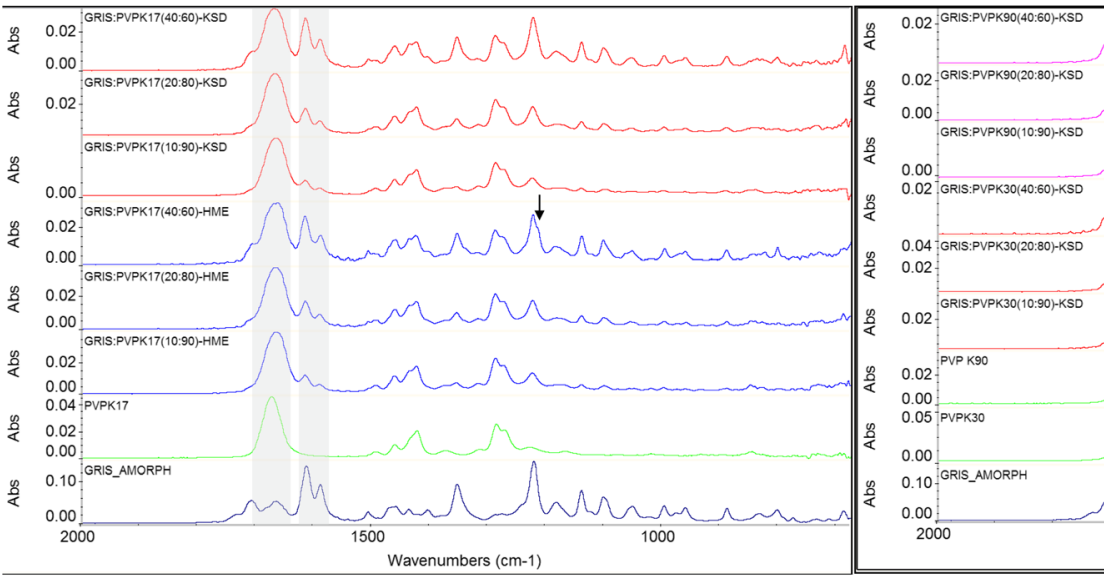

Pro
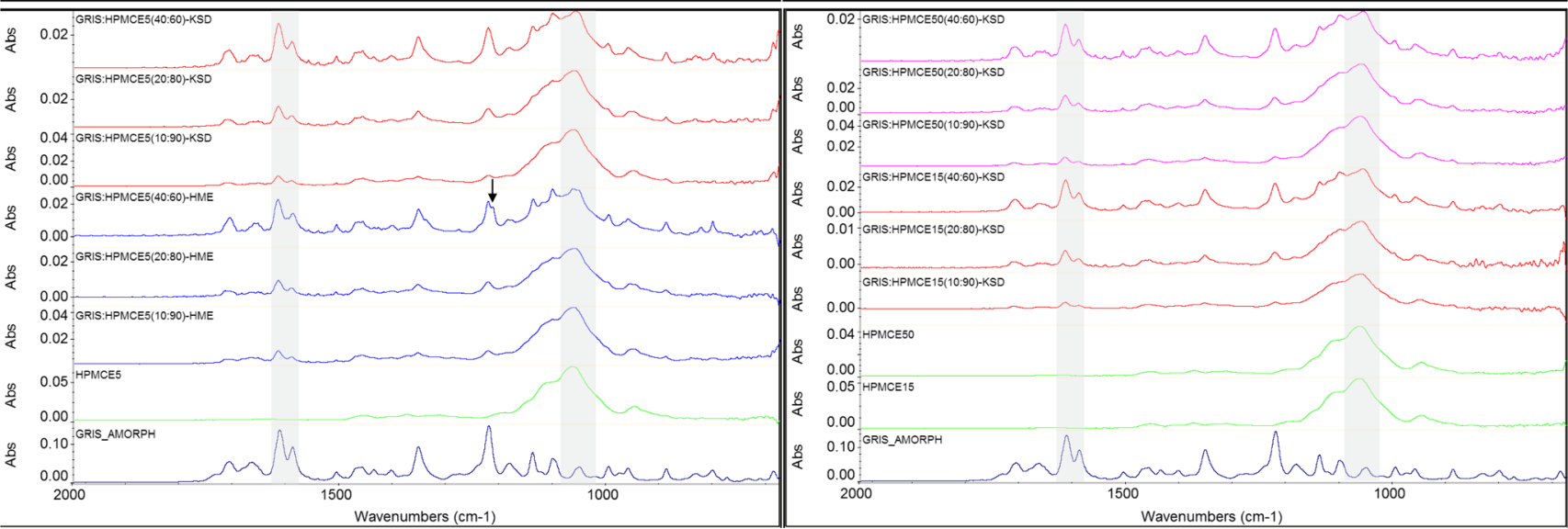

Fig. 4. FT-IR spectrum (from bottom to top) of GRIS amorphous drug (--), polymer (--), HME processed dispersions (--), and KSD processed dispersions (--) (from $10 \%$ to $40 \%$ drug load) in a (PVP K17) and c (HPMC E5). KSD processed dispersions of PVPK30 (--) and PVP K90 (--) (from $10 \%$ to $40 \%$ drug load) in $\mathbf{b}$, and KSD processed dispersions of HPMC E15 (--) and HMPC E50 (--) (from $10 \%$ to $40 \%$ drug load) in d. Features corresponding to crystalline drug are marked with arrows and regions of interest are shaded

conditions used for the 10 and $20 \%$ drug load, possibly due to plasticization by the drug that resulted in a more rapid heating rate that may have exceeded the degradation temperature of the polymer. A higher processing speed was used for the $40 \%$ drug load formulation using PVP K30, but the ejection temperature was the still set at the $T_{\mathrm{g}}$ of the polymer. Trace crystallinity was seen in the $40 \%$ drug load PVP K17 and K30 KSD samples by PXRD and was confirmed by a melt endotherm by DSC, a very small endotherm in the case of the 40\% PVP K30 sample. The higher processing speed used with the $40 \%$ PVP K30 sample may have yielded a more amorphous sample, whereas the $40 \%$ PVP K17 sample was processed at the same conditions used for the $10 \%$ and $20 \%$ drug load. By manipulating the processing speed and ejection temperature, the processing of these formulations could be improved further. As KSD allows for very short exposures to high temperatures and is not limited by melt viscosity, modifying processing parameters to further optimize the ASD preparation is an option for these polymers of high viscosity and small thermal processing windows; however, the processes for the 40\% PVP K17 and K30 formulations were not further optimized for this study.
As with the PVP, only the lowest viscosity grade of HPMC could be processed by HME. The HPMC E5 formulations were extruded $175^{\circ} \mathrm{C}$, with a die temperature of $180^{\circ} \mathrm{C}$ to reduce die pressure. HPMC E5 has a $T_{\mathrm{g}}$ of $178^{\circ} \mathrm{C}$, darkens at $190^{\circ} \mathrm{C}$, and degrades above $200^{\circ} \mathrm{C}(34,51)$. Although processed below $190^{\circ} \mathrm{C}$, discoloration (darkening) was still observed; however, transparent extrudates were able to be prepared for the $10 \%$ and $20 \%$ drug load formulations. It is not clear if the discoloration is due to a degradation mechanism of HPMC or incorporation of metal oxides from the extrusion barrel due to the high melt viscosity and stress as has been proposed (28) or both. Additionally, trace drug degradation below detectable levels could contribute to the discoloration observed; however, GRIS has been shown to be thermally stable even when held at $223^{\circ} \mathrm{C}$ for $3 \mathrm{~h} \mathrm{(31).} \mathrm{The}$ $40 \%$ HPMC E5 formulation was phase separated and was milky in appearance. The processing temperature for the $40 \%$ HPMC E5 formulation was not increased, as discoloration was already significant. Extrusion attempts with HPMC E15 resulted in high torque alarms and high die pressures; extrusion with HPMC E50 was not conducted based on the limitations seen with HPMC E15. 

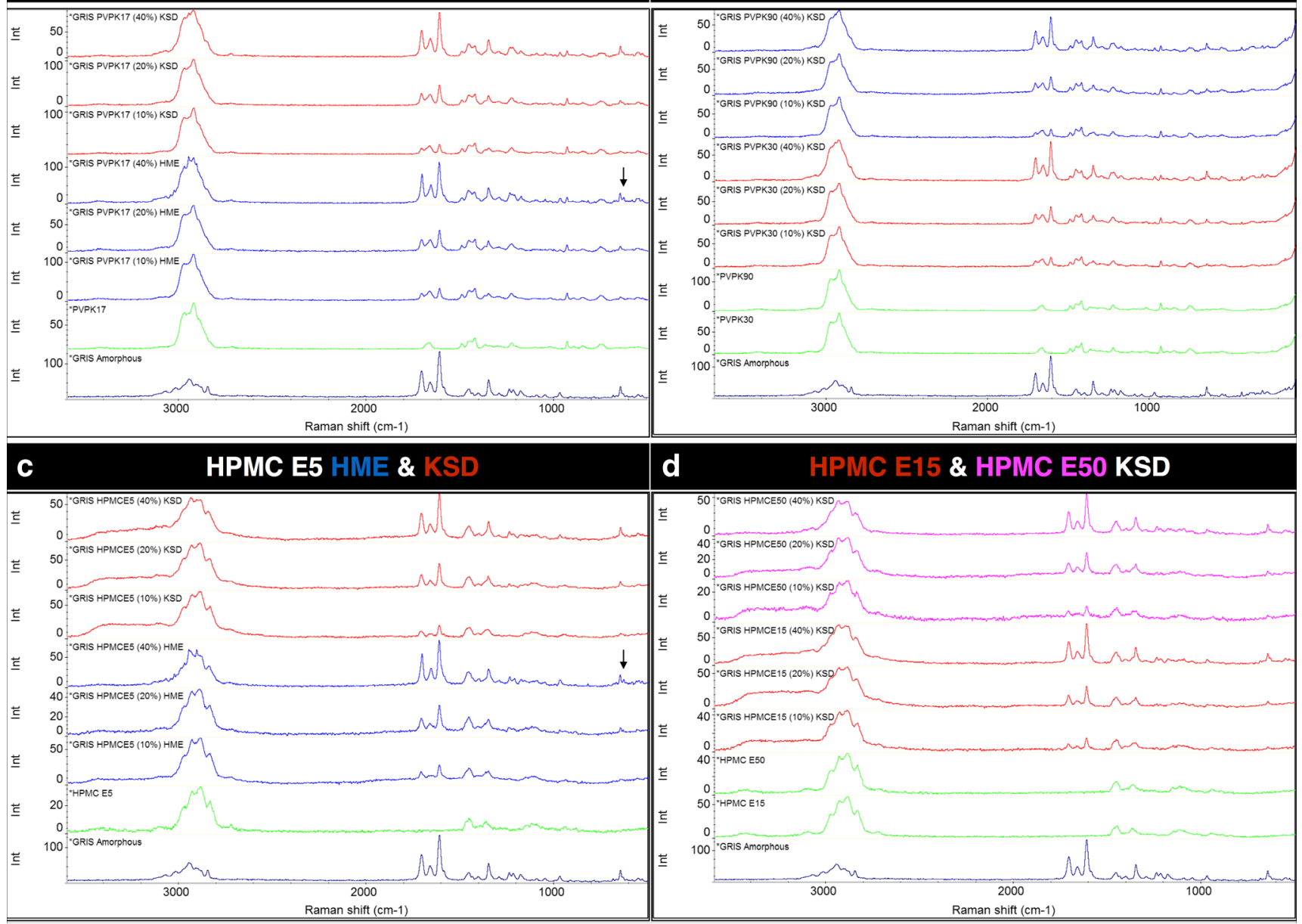

Fig. 5. FT-Raman spectrum (from bottom to top) of GRIS amorphous drug (- -), polymer (--), HME processed dispersions (--), and KSD processed dispersions (- ) (from 10\% to 40\% drug load) in a (PVP K17) and $\mathbf{c}$ (HPMC E5). KSD processed dispersions of PVPK30 (- -) and PVP K90 (--) (from $10 \%$ to $40 \%$ drug load) in $\mathbf{b}$, and KSD processed dispersions of HPMC E15 (--) and HMPC E50 (--) (from $10 \%$ to $40 \%$ drug load) in d. Features corresponding to crystalline drug are marked with arrows

The rheological and thermal properties of cellulosic polymers were recently investigated, with no extrudable temperature range of neat HPMC E (6cps) below its degradation temperature identified due to the high viscosity of the polymer (52). Extrusion with HPMC has been previously conducted with the low viscosity grades available $(19,47,53)$ and often still incorporates the use of a plasticizer to reduce processing temperature. Extrusion experiments with higher molecular weight grades of HPMC have been studied and consistently yield high torque loads and significant browning $(28,51)$. Coppens et al. conducted thermal and rheological characterization of HPMC E5 and HPMC E4M and found that both the low and high viscosity grades of HPMC showed substantial discoloration and high average torque, indicating challenges in extrusion without the use of a plasticizer. Of the three polymers studied by Coppens' group, HPMC had the narrowest processing window for HME. Hughey et al. showed that even extrusion at $180^{\circ} \mathrm{C}$ with low shear, meaning no mixing elements on the screw configuration, showed significant darkening of HPMC E50. Attempts to lower processing temperature to reduce browning resulted in high torque loads, further illustrating the narrow processing window of HPMC by HME.
All three HPMC grades and drug loads could be processed by KSD in this study. Ejection temperatures were set at $150^{\circ} \mathrm{C}$ for HPMC E5 and $160^{\circ} \mathrm{C}$ for HPMC E15 and E50, $10^{\circ} \mathrm{C}-20^{\circ} \mathrm{C}$ below $T_{\mathrm{g}}$ of the polymer. The processing speed was set at $2800 \mathrm{rpm}$, higher than what was utilized for processing the PVP formulations. The lower ejection temperature and higher processing speed were utilized to reduce the darkening that has been seen at temperatures as low as $175^{\circ} \mathrm{C}$. The darkening was significantly reduced when compared to the HPMC E5 HME processed material (Fig. 1). This was aligned with the findings of Hughey et al. (2012) that the reduced thermal exposure during KSD processing yields less polymer degradation. All HPMC grades and drug loads processed on the KSD were confirmed to be amorphous via PXRD analysis. Melt endotherms were seen in the higher drug loads in DSC analysis, but this was attributed to recrystallization upon heating. While there is potential that DSC could have a lower limit of detection for trace crystals compared to PXRD that would attribute to the melt endotherms observed, similar recrystallization exotherms were not observed in the PVP samples that did contain trace crystals as observed by PXRD and DSC; thus, the melt endotherms were solely attributed to 

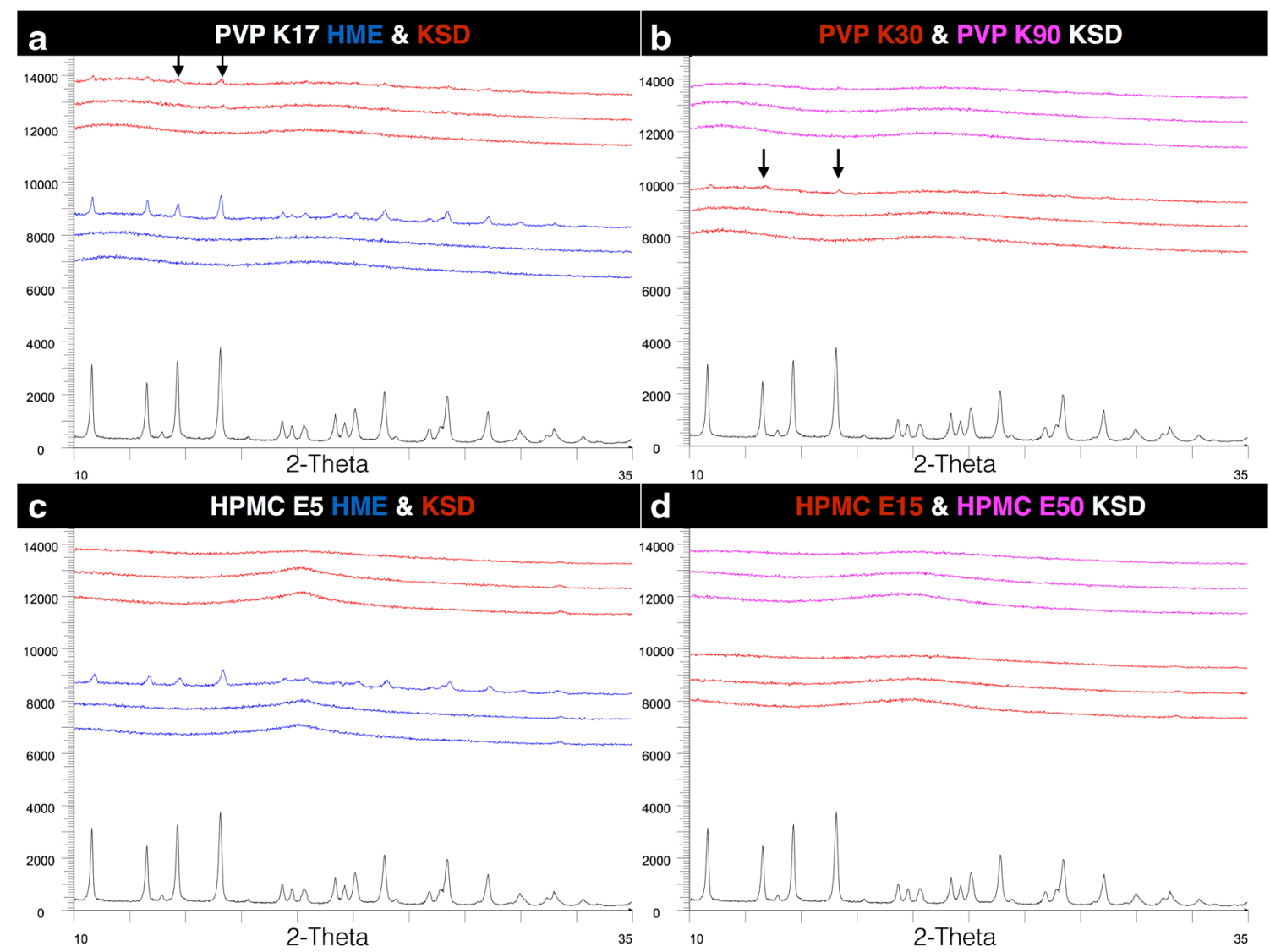

Fig. 6. PXRD profiles from samples stored at $40^{\circ} \mathrm{C} / 43 \% \mathrm{RH}$ for 6 months (from bottom to top) of GRIS crystalline drug (--), HME processed dispersions (--), and KSD processed dispersions (--) (from $10 \%$ to $40 \%$ drug load) in a (PVP K17) and c (HPMC E5). KSD processed dispersions of PVPK30 (--) and PVP K90 (--) (from 10\% to 40\% drug load) in b, and KSD processed dispersions of HPMC E15 (--) and HMPC E50 (--) (from $10 \%$ to $40 \%$ drug load) in d. Areas of observed trace crystallinity are marked with arrows

the analysis method in the HPMC samples. This is indicative of increased molecular mobility above the compositions $T_{\mathrm{g}}$, which promotes recrystallization; however, with relatively high $T_{\mathrm{g}} \mathrm{s}$ of the GRIS/HPMC compositions (greater than $88^{\circ} \mathrm{C}$ ) and the fact that HPMC is not hygroscopic, it is probable that physical stability can be maintained with appropriate packaging and storage conditions.

The stereo microscopic images clearly show that the short residence times of the KSD process lead to a reduction in discoloration of the polymer. However, they also show that the KSD processed samples are not transparent, and thus, visual clarity cannot be used as a quality check for amorphous conversion as is typical of HME processed amorphous dispersions. The opacity in the KSD processed samples was determined to be due the entrapped air in the ejected material, as observed in the X-ray CT images. It is important to note these samples were manually quenched between aluminum plates, which does not match the die pressures encountered in the extrusion process. If the ejected KSD material were quenched with a press, rather than manually between aluminum plates, the increased pressure would release this entrapped air similar in function to the pressure of the extrusion die. In this study, the downstream milling process likely releases much of this air, though some residual porosity is observed in the milled particles, especially for larger particle sizes. It is unclear how this porosity would affect downstream processing or dissolution rate as this was outside of the scope of this study, though other researchers have specifically attempted to increase the porosity of extruded material by injection of supercritical carbon dioxide in order to enhance dissolution and improve milling efficiency (54).

The ability to process ASDs with higher molecular weight polymers is advantageous, as it allows for increased stabilization against recrystallization by the high-viscosity environment provided by these polymers $(28,49,55,56)$. Miller et al. showed that HPMC E50 was able to provide the greatest stabilization of itraconazole, when compared to HPMC E5, PVP K12, and PVP K90. Chaudhari et al. showed that both PVP K90 and HPMC E50 allowed for the highest maintenance of dissolved indomethacin when compared to the lower molecular weight grades of PVP and HPMC. The ability to process the higher molecular weight grades of both PVP and HPMC by KSD, as shown in this study, provides the ability to prepare ASDs with the polymer that will lead to the optimal stability in the solid state $(12,56)$ and during dissolution. Additionally, the ability to readily produce ASDs with higher drug loads using KSD enables smaller dosage forms and/or reduced pill burden, resulting in improved patient compliance (57). Potentially, with further optimization in screw design and increased shear rates, higher drug loads could have been achieved by HME.

GRIS has been shown to undergo rapid crystallization below and above the $T_{\mathrm{g}}$ of the drug $(31,58)$; however, in this study, ASDs were able to be prepared at $10 \%$ and $20 \%$ drug 
load with the low viscosity grades of PVP and HPMC by HME, as well as up to $40 \%$ drug load in PVP K90 and with all grades of HPMC using KSD. In these systems, no physical or chemical changes were observed for up to 6 months in open-dish conditions, demonstrating the effectiveness of these systems to prevent recrystallization even for a drug that is known to rapidly crystallize.

\section{CONCLUSION}

In this study, two thermal processing technologies were evaluated utilizing the model compound GRIS with a range of molecular weight grades of PVP and HPMC. ASDs were prepared by HME and KSD processing, with the latter able to more readily render amorphous dispersions of higher drug loads and with polymers of higher molecular weight. Specifically, this study is the first to demonstrate thermal processing of ASDs utilizing high molecular weight grades of PVP (PVP K30 and PVP K90) without the use of a plasticizer. X-ray CT was used as a non-destructive technique to investigate the differences in internal porosity of solid samples produced by each process, which provided complementary data compared to more common external imaging techniques such as SEM and stereo microscopy. PXRD and MDSC showed that amorphous dispersions could be prepared as high as $20 \%$ drug load with $\mathrm{HME}$ and 40\% drug load with KSD (PVPK90 and all HPMC grades). Spectroscopic investigations with FT-IR and FT-Raman showed no drug-polymer interactions. The ASDs produced were shown to be stable for up to 6 months at accelerated, open-dish conditions.

\section{ACKNOWLEDGMENTS}

Some of this work was presented at the AAPS Annual Meeting and Exposition, San Diego, CA, 2014. The authors would like to acknowledge Kyle Ford for his assistance in the lab and Jessie Maisano for her help and guidance on the X-ray CT studies.

\section{REFERENCES}

1. Lipinski CA, Lombardo F, Dominy BW, Feeney PJ. Experimental and computational approaches to estimate solubility and permeability in drug discovery and development settings. Adv Drug Deliv Rev. 2001;46(1-3):3-26. doi:10.1016/S0169-409X(00)001290 .

2. Dahan A, Miller J, Amidon G. Prediction of solubility and permeability class membership: provisional BCS classification of the world's top oral drugs. AAPS J. 2009;11(4):740-6. doi:10.1208/ s12248-009-9144-x.

3. Buckley ST, Frank KJ, Fricker G, Brandl M. Biopharmaceutical classification of poorly soluble drugs with respect to "enabling formulations”. Eur J Pharm Sci. 2013;50(1):8-16. doi:10.1016/ j.ejps.2013.04.002.

4. Blagden N, de Matas M, Gavan PT, York P. Crystal engineering of active pharmaceutical ingredients to improve solubility and dissolution rates. Adv Drug Deliv Rev. 2007;59(7):617-30. doi:10.1016/j.addr.2007.05.011.

5. $\mathrm{Xu} \mathrm{W,} \mathrm{Riikonen} \mathrm{J,} \mathrm{Lehto} \mathrm{V-P.} \mathrm{Mesoporous} \mathrm{systems} \mathrm{for} \mathrm{poorly}$ soluble drugs. Int J Pharm. 2013;453(1):181-97. doi:10.1016/ j.ijpharm.2012.09.008.

6. Williams III RO, Watts AB, Miller DA, editors. Formulating poorly water soluble drugs. New York: Springer; 2012.
7. Brouwers J, Brewster ME, Augustijns P. Supersaturating drug delivery systems: the answer to solubility-limited oral bioavailability? J Pharm Sci. 2009;98(8):2549-72. doi:10.1002/jps.21650.

8. Linn M, Collnot E-M, Djuric D, Hempel K, Fabian E, Kolter K, et al. Soluplus ${ }^{\circledR}$ as an effective absorption enhancer of poorly soluble drugs in vitro and in vivo. Eur J Pharm Sci. 2012;45(3):336-43. doi:10.1016/j.ejps.2011.11.025.

9. Lindfors L, Forssén S, Westergren J, Olsson U. Nucleation and crystal growth in supersaturated solutions of a model drug. J Colloid Interface Sci. 2008;325(2):404-13. doi:10.1016/ j.jcis.2008.05.034.

10. Ueda K, Higashi K, Kataoka M, Yamashita S, Yamamoto K, Moribe K. Inhibition mechanism of hydroxypropyl methylcellulose acetate succinate on drug crystallization in gastrointestinal fluid and drug permeability from a supersaturated solution. Eur J Pharm Sci. 2014;62:293-300. doi:10.1016/j.ejps.2014.06.007.

11. Alonzo DE, Raina S, Zhou D, Gao Y, Zhang GGZ, Taylor LS. Characterizing the impact of hydroxypropylmethyl cellulose on the growth and nucleation kinetics of felodipine from supersaturated solutions. Cryst Growth Des. 2012;12(3):1538-47. doi:10.1021/cg201590j.

12. Van den Mooter G, Wuyts M, Blaton N, Busson R, Grobet P, Augustijns $\mathrm{P}$, et al. Physical stabilisation of amorphous ketoconazole in solid dispersions with polyvinylpyrrolidone K25. Eur J Pharm Sci. 2001;12(3):261-9.

13. Brough C, Williams Iii RO. Amorphous solid dispersions and nano-crystal technologies for poorly water-soluble drug delivery. Int J Pharm. 2013;453(1):157-66. doi:10.1016/ j.ijpharm.2013.05.061.

14. Masters K. Spray drying handbook. Harlow: Longman Scientific \& Technical; 1991.

15. Paudel A, Worku ZA, Meeus J, Guns S, Van den Mooter G. Manufacturing of solid dispersions of poorly water soluble drugs by spray drying: formulation and process considerations. Int $\mathrm{J}$ Pharm. 2013;453(1):253-84. doi:10.1016/j.ijpharm.2012.07.015.

16. Breitenbach J. Melt extrusion: from process to drug delivery technology. Eur J Pharm Biopharm. 2002;54(2):107-17. doi:10.1016/S0939-6411(02)00061-9.

17. Zhang Y, Luo R, Chen Y, Ke X, Hu D, Han M. Application of carrier and plasticizer to improve the dissolution and bioavailability of poorly water-soluble baicalein by hot melt extrusion. AAPS PharmSciTech. 2014;15(3):560-8. doi:10.1208/s12249-0130071-X.

18. Maddineni S, Battu SK, Morott J, Majumdar S, Murthy SN, Repka MA. Influence of process and formulation parameters on dissolution and stability characteristics of Kollidon(R) VA 64 hot-melt extrudates. AAPS PharmSciTech. 2015;16(2):444-54. doi:10.1208/s12249-014-0226-4.

19. Ghosh I, Snyder J, Vippagunta R, Alvine M, Vakil R, Tong W-Q, et al. Comparison of HPMC based polymers performance as carriers for manufacture of solid dispersions using the melt extruder. Int J Pharm. 2011;419(1-2):12-9. doi:10.1016/ j.ijpharm.2011.05.073.

20. Capone C, Di Landro L, Inzoli F, Penco M, Sartore L. Thermal and mechanical degradation during polymer extrusion processing. Polym Eng Sci. 2007;47(11):1813-9. doi:10.1002/pen.20882.

21. Sarode AL, Obara S, Tanno FK, Sandhu H, Iyer R, Shah N. Stability assessment of hypromellose acetate succinate (HPMCAS) NF for application in hot melt extrusion (HME). Carbohydr Polym.2014;101:146-53. doi:10.1016/ j.carbpol.2013.09.017.

22. El'darov EG, Mamedov FV, Gol'dberg VM, Zaikov GE. A kinetic model of polymer degradation during extrusion. Polym Degrad Stab. 1996;51(3):271-9. doi:10.1016/01413910(95)00160-3.

23. Miller DA, Keen JM. KinetiSol®-based amorphous solid dispersions. Amorphous Solid Dispersions. Springer; 2014. p. 567-77.

24. DiNunzio JC, Brough C, Miller DA, Williams RO, McGinity JW. Fusion processing of itraconazole solid dispersions by KinetiSol ${ }^{\circ}$ dispersing: a comparative study to hot melt extrusion. J Pharm Sci. 2010;99(3):1239-53. doi:10.1002/jps.21893.

25. Hughey J, DiNunzio J, Bennett R, Brough C, Miller D, Ma H, et al. Dissolution enhancement of a drug exhibiting thermal and acidic decomposition characteristics by fusion processing: a comparative study of hot melt extrusion and KinetiSol® Dispersing. 
AAPS PharmSciTech. 2010;11(2):760-74. doi:10.1208/s12249010-9431-y.

26. DiNunzio JC, Hughey JR, Brough C, Miller DA, Williams Iii RO, McGinity JW. Production of advanced solid dispersions for enhanced bioavailability of itraconazole using KinetiSol® Dispersing. Drug Dev Ind Pharm. 2010;36(9):1064-78. doi:10.3109/ 03639041003652973.

27. DiNunzio JC, Brough C, Hughey JR, Miller DA, Williams Iii RO, McGinity JW. Fusion production of solid dispersions containing a heat-sensitive active ingredient by hot melt extrusion and KinetiSol® Dispersing. Eur J Pharm Biopharm. 2010;74(2):34051. doi:10.1016/j.ejpb.2009.09.007.

28. Hughey JR, Keen JM, Miller DA, Brough C, McGinity JW. Preparation and characterization of fusion processed solid dispersions containing a viscous thermally labile polymeric carrier. Int J Pharm. 2012;438(1-2):11-9. doi:10.1016/ j.ijpharm.2012.08.032.

29. DiNunzio JC, Brough C, Miller DA, Williams Iii RO, McGinity JW. Applications of KinetiSol ${ }^{\circledR}$ Dispersing for the production of plasticizer free amorphous solid dispersions. Eur J Pharm Sci. 2010;40(3):179-87. doi:10.1016/j.ejps.2010.03.002.

30. Hughey JR, Keen JM, Brough C, Saeger S, McGinity JW. Thermal processing of a poorly water-soluble drug substance exhibiting a high melting point: the utility of KinetiSol ${ }^{\circledR}$ Dispersing. Int J Pharm. 2011;419(1-2):222-30. doi:10.1016/ j.ijpharm.2011.08.007.

31. Zhou D, Zhang GG, Law D, Grant DJ, Schmitt EA. Thermodynamics, molecular mobility and crystallization kinetics of amorphous griseofulvin. Mol Pharm. 2008;5(6):927-36. doi:10.1021/ mp800169g.

32. Yamamura S, Takahira R, Momose Y. Crystallization kinetics of amorphous griseofulvin by pattern fitting procedure using X-ray diffraction data. Pharm Res. 2007;24(5):880-7. doi:10.1007/ s11095-006-9204-1.

33. Trasi NS, Byrn SR. Mechanically induced amorphization of drugs: a study of the thermal behavior of cryomilled compounds. AAPS PharmSciTech. 2012;13(3):772-84. doi:10.1208/s12249012-9801-8.

34. Rowe RC, Sheskey PJ, Owen SC, American Pharmacists Association. R2 Library (Online service). Handbook of pharmaceutical excipients. In: Pharmaceutical Press; American Pharmacists Association; 2006. http://www.UTXA.eblib.com/patron/ FullRecord.aspx? $\mathrm{p}=363944$.

35. Keary CM. Characterization of METHOCEL cellulose ethers by aqueous SEC with multiple detectors. Carbohydr Polym. 2001;45(3):293-303. doi:10.1016/S0144-8617(00)00263-0.

36. Kolter K, Karl M, Gryczke A, Ludwigshafen am Rhein B. Hotmelt extrusion with BASF pharma polymers: extrusion compendium, 2nd ed. BASF; 2012.

37. Nair R, Nyamweya N, Gonen S, Martinez-Miranda LJ, Hoag SW. Influence of various drugs on the glass transition temperature of poly(vinylpyrrolidone): a thermodynamic and spectroscopic investigation. Int J Pharm. 2001;225(1-2):83-96.

38. Feng T, Pinal R, Carvajal MT. Process induced disorder in crystalline materials: differentiating defective crystals from the amorphous form of griseofulvin. J Pharm Sci. 2008;97(8):3207-21. doi:10.1002/jps.21219.

39. Milne M, Liebenberg W, Aucamp M. The stabilization of amorphous zopiclone in an amorphous solid dispersion. AAPS PharmSciTech. 2015. doi:10.1208/s12249-015-0302-4.

40. Verma S, Rudraraju VS. Wetting kinetics: an alternative approach towards understanding the enhanced dissolution rate for amorphous solid dispersion of a poorly soluble drug. AAPS PharmSciTech. 2015. doi:10.1208/s12249-014-0281-x.

41. Leuner C, Dressman J. Improving drug solubility for oral delivery using solid dispersions. Eur J Pharm Biopharm. 2000;50(1):47-60. doi:10.1016/S0939-6411(00)00076-X.

42. Kestur US, Lee H, Santiago D, Rinaldi C, Won YY, Taylor LS. Effects of the molecular weight and concentration of polymer additives, and temperature on the melt crystallization kinetics of a small drug molecule. Cryst Growth Des. 2010;10(8):3585-95. doi:10.1021/cg1004853.

43. Al-Obaidi H, Buckton G. Evaluation of griseofulvin binary and ternary solid dispersions with HPMCAS. AAPS PharmSciTech. 2009;10(4):1172-7. doi:10.1208/s12249-009-9319-x.

44. Al-Obaidi H, Ke P, Brocchini S, Buckton G. Characterization and stability of ternary solid dispersions with PVP and PHPMA. Int J Pharm. 2011;419(1-2):20-7. doi:10.1016/j.ijpharm.2011.06.052.

45. Karl M, Nalawade S, Maschke A, Djuric D, Kolter K. Suitability of pure and plasticized polymers for hot melt extrusion. The 37th Annual Meeting and Exposition of the Controlled Release Society. Portland: BASF SE, Ludwigshafen, Germany; 2010.

46. Fousteris E, Tarantili P, Karavas E, Bikiaris D. Poly(vinyl pyrrolidone)-poloxamer-188 solid dispersions prepared by hot melt extrusion. J Therm Anal Calorim. 2013;113(3):1037-47. doi:10.1007/s10973-012-2885-2.

47. Ghebremeskel AN, Vemavarapu C, Lodaya M. Use of surfactants as plasticizers in preparing solid dispersions of poorly soluble API: selection of polymer-surfactant combinations using solubility parameters and testing the processability. Int J Pharm. 2007;328(2):119-29. doi:10.1016/j.ijpharm.2006.08.010.

48. Chokshi RJ, Sandhu HK, Iyer RM, Shah NH, Malick AW, Zia H. Characterization of physico-mechanical properties of indomethacin and polymers to assess their suitability for hot-melt extrusion process as a means to manufacture solid dispersion/solution. J Pharm Sci. 2005;94(11):2463-74. doi:10.1002/jps.20385.

49. Miller DA, DiNunzio JC, Yang W, McGinity JW, Williams RO. Enhanced in vivo absorption of itraconazole via stabilization of supersaturation following acidic-to-neutral $\mathrm{pH}$ transition. Drug Dev Ind Pharm. 2008;34(8):890-902. doi:10.1080/ 03639040801929273.

50. Gupta SS, Meena A, Parikh T, Serajuddin AT. Investigation of thermal and viscoelastic properties of polymers relevant to hot melt extrusion, I: Polyvinylpyrrolidone and related polymers. J Excipients Food Chem. 2014;5(1):32-45.

51. Coppens K, Hall M, Larsen P, Mitchell S, Nguyen P, Read M, et al., editors. Thermal and rheological evaluation of pharmaceutical excipients for hot melt extrusion. AAPS Annual Meeting and Exposition, Baltimore, MD; 2004.

52. Meena A, Parikh T, Gupta SS, Serajuddin AT. Investigation of thermal and viscoelastic properties of polymers relevant to hot melt extrusion, II: Cellulosic polymers. J Excipients Food Chem. 2014;5(1):46-55.

53. Six K, Berghmans H, Leuner C, Dressman J, Van Werde K, Mullens $\mathrm{J}$, et al. Characterization of solid dispersions of itraconazole and hydroxypropylmethylcellulose prepared by melt extrusion, part II. Pharm Res. 2003;20(7):1047-54. doi:10.1023/ A:1024414423779.

54. Verreck G, Decorte A, Li HB, Tomasko D, Arien A, Peeters J, et al. The effect of pressurized carbon dioxide as a plasticizer and foaming agent on the hot melt extrusion process and extrudate properties of pharmaceutical polymers. J Supercrit Fluids. 2006;38(3):383-91. doi:10.1016/J.Supflu.2005.11.022.

55. Chaudhari SP, Dave RH. To study the effect of different molecular weight polymers (polyvinylpyrollidone (PVP, Plasdone) and hydroxypropyl methyl cellulose (HPMC, Methocel)) as a potential antiprecipitating (AP) agents on supersaturation. American Association of Pharmaceutical Scientists Annual Meeting and Exposition. San Antonio, TX, USA; 2013.

56. Aso Y, Yoshioka S, Miyazaki T, Kawanishi T. Feasibility of $19 \mathrm{~F}-$ NMR for assessing the molecular mobility of flufenamic acid in solid dispersions. Chem Pharm Bull. 2009;57(1):61-4.

57. Hagendorff A, Freytag S, Müller A, Klebs S. Pill burden in hypertensive patients treated with single-pill combination therapy—an observational study. Adv Ther. 2013;30(4):406-19. doi:10.1007/s12325-013-0018-3.

58. Baird JA, Van Eerdenbrugh B, Taylor LS. A classification system to assess the crystallization tendency of organic molecules from undercooled melts. J Pharm Sci. 2010;99(9):3787-806. doi:10.1002/jps.22197. 